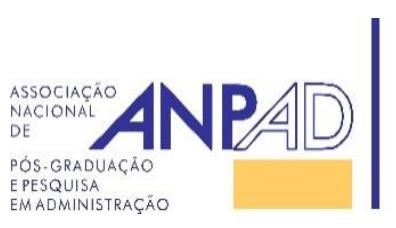
Available online at http://www.anpad.org.br/bar
BAR, Rio de Janeiro v. 13, n. 3, art. 2, e160014, July/Sept. 2016

\title{
The Wonderful, Magnanimous, Spectacular and Possible World of Traveling Circuses in Brazil
}

Eloisio Moulin de Souza ${ }^{2}$

Universidade Federal de Minas Gerais ${ }^{1}$ Universidade Federal do Espirito Santo ${ }^{2}$

Received 10 February 2016; received in revised form in 30 June 2016; accepted in 5 August 2016; published online 9 September 2016. 


\begin{abstract}
This paper aims to examine the everyday management of traveling circuses in Brazil by looking for the practices and strategies that allow them to survive over time. To this end, it relies on theories about the management of everyday life developed by De Certeau. The discourses of individuals working at small, medium and large circuses is analysed to reveal their routine strategies and tactics. This analysis reveals the complexities and contradictions involved in the management of such organizations, while debating the strategies and tactics developed within them, as well as the everyday process of creation-invention. Circuses are practiced organizations like any other and, as such, they are part of the local social-historical reality, reconstructing themselves every day.
\end{abstract}

Key words: circus; strategies; tactics; management of everyday life; routine. 


\section{Introduction}

This paper approaches management from the perspective of the wonderful, magnanimous, spectacular and possible world of circus organizations. It aims to discuss the everyday management of traveling circuses in Brazil by looking for the practices and strategies that allow them to survive over time. These are defined herein as circuses representing complex organizations that, due to their particular nature, are built on wheels, have no fixed address, and show certain particularities in their daily management. Circuses are organizations operating in a physical structure made of canvas, with a ring for performances. Their primary purpose is to entertain a particular audience. Their origins refer back to equestrian artists, acrobats of military background, and families of jugglers, street artists, and gypsies, all united around the circus show (Silva, 2007).

In the field of management, Parker (2011) has studied circuses by analysing them as mobile and complex organizations that profit from moving people and objects around. In fact, spectators often have no idea of all the organizational structure involved in circus performances. Several institutional and economic mechanisms are necessary for magic and miracle to take place in the ring. The association of the word circus with chaos and ineffectiveness does not seem to find support in the reality of circus organizations, which are actually highly complex and organized. The spectacle is designed for playful fantasy to prevail, while concealing the managerial, organizational and economic aspects; however, these organizations aim to profit as all others. Parker argues that circuses are not reducible to a set of economic or organizational relationships, nor to the fantastic, magical or romanticized idealization of an itinerant community. Instead, the circus show is a product that comprises economic and organizational aspects.

However, the Brazilian circuses studied in this paper have shown certain peculiarities. In the national context, large physical structures with formal labour relations - such as those addressed by Parker (2011) - are seldom. In Brazil, organizational forms stemming from family businesses prevail, originating with the arrival of the first circus families in Brazil back in the eighteenth century (Duarte, 1995). The Brazilian circus, according to Silva $(2006,2007)$ and Bolognesi (2003), also operates based on the creation of an atmosphere of enchantment and magic aimed at attracting audiences. However, family values and nostalgia are elements that national circuses attempt to perpetuate. This decision may explain the insistence of Brazilian circuses on fostering a traditional circus lifestyle. Such tradition is expressed through customs of knowledge transmission in circus households and through a concept of how a circus performance should be carried out. In the routine of a circus, daily practices unfold in the ways subjects create to preserve the circus mobility, the familiar unity, and a certain artistic concept. In other words, subjects attempt to remain a circus, while also incorporating reinvention and reinterpretation in their daily lives.

The management of everyday life (Carrieri, Perdigão, \& Aguiar, 2014; Fleming \& Sturdy, 2009; Hancock \& Tyler, 2009; Maravelias, 2011) is taken herein as a guideline for the study of circus organizations. This approach to management focuses on the study of ordinary individuals, that is, the everyday practices and knowledge that portray everyday life in contemporary society. This proposition aims to deconstruct the categories of management and organization studies, challenging theories that take reality as given and produce instruments to sustain a rational ordering of the world without reflecting on its true reality.

To expand this investigation, this paper examines management in relation to the theoretical category of everyday life, especially from the perspective of De Certeau (1990a, 1990b). Yet, it has to be mentioned that Lefebvre (1974) and Heller (1984) have also discussed such a category in their works. These authors perceive everyday life as the locus for the possibility of becoming. The ordinary element of everyday life represents a possibility for (extra) ordinariness to happen, through the potential it holds for reflexivity. Heller (1984) defines everyday life as a space for creation and alienation through the actions of individuals and Lefebvre (1974) defines it is a locus for praxis and a space for human experimentation. However, this paper is based on the work of De Certeau (1990a, 1990b), who defines 
it as creation-invention, valuing the art of doing, the resistance tactics, the power strategies, and the cultural meanings constructed by subjects.

This article is organized in the following five sections: (a) this introduction; (b) a review of the concepts of daily life and ordinariness; (c) information about the methodology used in the production of narratives about popular circuses; (d) a presentation of key topics on the management of everyday life; (e) a presentation of the main findings on extraordinary operations as observed in ordinary life.

\section{The Possibility of (Extra) Ordinariness in Everyday Life}

The proposal of working with the management of everyday life derives from the goal of redefining the very concept of management. Perceiving management as ordinary can expand the possibilities of what managing and organizing mean. On one hand, it characterizes the impossibilities and limitations of instrumental management before reality and, on the other hand, the everyday life of organizations. The management of everyday life is found in Cooper (1986); Parker (2002); Carrieri (2012); Herners and Maitlis (2010); Herners (2008); and Carrieri, Perdigão and Aguiar (2014).

The aforementioned authors start from the deconstruction of the term management and its typical uses, in order to shift it from its dominant contexts - in which they have been arranged as instruments of power. These researchers propose the study of ordinariness, focusing on ordinary individuals, their practices and the knowledge that characterize a particular set of managing practices taking place every day. This approach also addresses the everyday world, which is the very space for the unlimited production of rationalities at different periods. Due to its heterogeneity, everyday life distinguishes itself through the possibilities of becoming.

In order to situate the management of everyday life in this paper, we emphasize the review carried out by Gardiner (2000), which analysed the work of De Certeau, Lefebvre, Heller, Debord, Foucault, among other authors who approached everyday life to expose its contradictions, while unveiling its potential. From this perspective, the study of everyday life has been historically linked with life's dynamics and has been characterized as a complex, contradictory incorporator of great reflexivity. The reflexivity enables subjects to adapt to different or new situations and explains the historical and cultural variability manifested in the daily life of these subjects. This analysis shows that although everyday life can display static and non-reflective characteristics, it is also capable of moments of surprising dynamism, profound insight, and boundless creativity.

This theoretical search treats whatever is ordinary and manifested in daily life as potentially extraordinary domains. Critical theories on everyday life have questioned functional reasoning and acknowledged that human life presents various non-rational trends that cannot be captured by the reductionist explicative models favoured by positivist social sciences. In the management of everyday life, marginalized spaces and practices are privileged, as well as what is non-official and decentralized. In addition, there is interest in giving voice to those who are not heard and strong criticism against dualistic analyses of reality and the reduction of complex social practices to mere linguistic or discursive operations (Gardiner, 2000).

Everyday life is heterogeneous and permeated by hierarchical practices. Within it, actions occur without prior reflection, based on momentary judgments and guided by reflexive reproduction. Hence, the coexistence and succession of heterogeneous activities make the space of everyday life prone to alienation (Heller, 1984). Furthermore, in everyday life the production and reproduction of social relations take place, that is, the very production of human beings over the course of history. Within the historical context of modernity, human activities become fragmented, creating a gap among subjects, their subjectivities and their practices. The work that was previously imaginative and creative has been transformed into ordinary and mercantilized forms where the space is simultaneously a tool of production and control, of action and thinking (Lefebvre, 1974). 
In the space of cities, work and routine, the everyday representation would lie as an empirical object and as a form of mediation between what is specific and what is universal. In modernity, everyday life in modernity is perceived under the rule of capital, dominant forms of work organization, the domain of space and time, and the voluntary and planned self-regulation of people's lives. It is in and through everyday life that capitalist social relations are produced and reproduced and, as such, it becomes a space for the production-consumption-production of practices and ideas (Goonewardena, Kipfer, Milgrom, \& Schmid, 2008; Levigard \& Barbosa, 2010).

Along these lines, Lefebvre (1974) had already perceived everyday life as negative, claiming that it was completely impregnated by routine, degraded and colonized by commodity and by the instrumentalized needs of States and capital. Therefore, the promise of a Total Man would be replaced by the passive and manipulated consumption of endless signals and images. The possibility of changing this reality would lie in overall social transformation, i.e., the creation of new cultural, economic and political relations.

In Lefebvre (1974) there is the so-called disenchantment with everyday reality, and the possibilities of alienation/emancipation of the subject dependent on changes in social structures. In Heller (1984) the subject has a relative degree of freedom to make choices, but experiences alienation through work in their daily lives. However, De Certeau (1990a, 1990b) proposes an opposite direction to these ideas about everyday life, always pointing to a position change, emancipation and creation of the subject and of popular culture. The author also questions the relationship between power and knowledge, underlining how cultural practices are objects of knowledge on the part of social groups and are always biased by the conventions of economic and social power. Accordingly, De Certeau proposes that academics work with popular culture from a perspective that confers legitimacy to cultural expressions and ownership of meanings among those who produce it, highlighting the irreducible multiplicity of social and cultural forms among humans (Gardiner, 2000).

This paper focuses on De Certeau's approach because of his more optimistic view of social reality than Heller and Lefebvre. De Certeau perceives everyday life as the basis for creation, invention, reinvention and recreation, through the arts of doing. These routine practices consist of subtle, inventive resistance tactics enacted by ordinary individuals who appropriate spaces and territories and reverse objects and codes, using them in their own way (Del Priore, 1997). That is, De Certeau approaches everyday life as the social space opened to the creative actions of ordinary individuals over time and such practices are the basis for the construction and deconstruction of cultural meanings (Harvey, 2002). Finally, everyday culture is studied as a part of people's lives, regarding the aspects of strategies and survival tactics, which are reinvented every day (Freitas, 2008).

For De Certeau (1990a, 1990b), everyday life is the space of creativity. Even with the alienation inherent in everyday life, routines, rules and habits, it is always possible to invent different practices, for the routine offers a certain degree of freedom of action and decision, as well as multiple possibilities. In face of dominant strategies, the tactics enacted by subjects in their everyday life are unveiled. For the author, there are (micro) exercises, i.e., certain tactics that oppose and confront strategies included in the routine by repression apparatuses and domination structures. Such structures are constantly open for practitioners and entrepreneurs to find cracks and breaches. The invention of everyday life would take place through the arts of doing, the hunter's cunning and the resistance tactics that can change objects and codes and establish the (re)appropriation of space and the way of using each of those.

De Certeau does not propose any closed system that may serve as a theoretical model, but demonstrates that within the apparent disorder of human words and actions, there are complex panoramas that can be intelligible for interested observers. "The everyday world - a world profuse in individuals, words, gestures, movements, things - houses the tactics of doing, the anonymous inventions, the deviation of norms, without confrontation, yet no less instituting" (Sousa, 2002, pp. 130131, our translation). Accordingly, the studies by De Certeau on everyday life assume that the consumption of ideas, values and goods by anonymous subjects are not, in any way, a passive and uniform practice, made of pure conformity to the impositions of markets and social powers. 
In a certain sense, this paper agrees with Gardiner (2000) who points out that, despite the differences among Heller, Lefebvre and De Certeau, to think about everyday life is to refer to the ordinariness that shelters extraordinariness. That is, the invention, the possibility, and the becoming that stand before the reproducibility of all aspects of the structures imposed on individuals, the reflexivity and the expression of subjects through praxis that entails emancipation, and the experiencing that comprises diversity at the expense of pasteurization. Everyday life is perceived herein as a locus that resists against thought domination and the commercialization and homogenization of experiences. It has an imaginative and symbolic dimension and its non-systematic and unpredictable quality make it a space for escape and resistance. It is up to researchers to capture the qualitative characteristics of reality and the signs of difference and otherness, or the extraordinariness in ordinariness.

In management, there is still a lack of research on the interpretations of the real world, from the people who actually work, drive and manage everyday life. These could constitute the empirical bias to focus on the narratives, interpretations, and testimonies of ordinary people, that is, of everyday life (Rowlinson \& Carter, 2002). This should prevent social scientists from carrying out studies that disregard reality, which consequently hinders the construction of social theories (Callinicos, 1989). Therefore, since the main concepts related to everyday life and their implications for empirical research have been explained, the next section presents the methodology adopted in this paper.

\section{The Seizure of Everyday Experiences and Social-Historical Narratives}

The circus organizations that comprise the body of this study are diverse, holding similarities, but also differences. As for size, they are small, medium, or large. However, as for the individuals who live, work and roam with such circuses, they are actually quite similar. The members of such organizations have the nomadic way of life in common and are organized in groups formed by individuals who work and reside in a rather particular universe: the circus world.

For this research, we visited 30 traveling circuses, with all selected through snowball sampling (Goodman, 1961). The interviews focused on the subjects' narratives, their stories and daily lives, while trying to grasp the organizational forms of the visited circuses. The narratives were collected by interview, since they are constructed through the narrator's experiences, world views, everyday lives and actions, at a given historic moment.

The surveyed was conducted between the years 2010 and 2013 and focused on traveling circuses circulating in Minas Gerais, Rio de Janeiro, Espírito Santo and São Paulo. Of the 30 circuses, 07 circuses were large, 09 medium and 14 small, with most family-owned and managed. A sample of 116 respondents were interviewed to collect the narratives about the circus routines. These included circus owners, their relatives, artists hired along with their entire family, as well as single men and women. By doing so, we have attempted to incorporate the diversity of circus subjects into this paper.

Interviews were unstructured, with only a basic list of questions that could guide further explanation of reality. As Garfinkel (1967) suggests, this technique allows understanding the artisanal practice of everyday life, interpreted at the very first degree by social actors in terms of their meanings. According to Goldenberg (2002), this method can reveal how individuals universalize the historical period they live in, through their everyday lives and practices. Therefore, based on the respondents' narratives, we have sought to discuss the relationship of individuals with the social context in which they are inserted. This should allow for the reconstruction of their experiences during their careers (Marre, 1991). 


\section{Several Circuses, One Objective: To Make the Audience Be Scared to Death and Laugh Their Butts Off}

To start the analysis of circus organizations, it is important to clarify a certain point. We observed that there is not such a thing as a single circus routine, but several of them, experienced by dissimilar social subjects. The field research shows that the word circus designates diverse objects, itinerant and non-itinerant work forms, family groups, theatre groups, street performers, complex business organizations, all representing different management and organizational structures. Hence, we found very specific management routines, due to the peculiarities and diversities of form of such organizations. However, this paper discusses the practices (themes) we have perceived as common to management, that is, the aspects of the circus routine found in these organizations, while seeking to outline a general view - defined by the subjects themselves - of the circus organizations in question.

We visited small circuses, which are defined by their physical capacity (less than 200 seats) and the number of subjects living at their expense. Some of these small circuses were encountered while they traveled through small towns or villages, and others on the outskirts of large urban spaces. A small number of artists result in a show with few variations, which consequently limits the circuses' ability to attract audiences. For that reason, the circuses in this category face the everyday possibility of becoming unable to move on. Among the circus we have called medium, there are differences as to what they can offer. These are composed of more than three family cores and can host larger audiences (more than 200 seats and less than 500) and have greater ability to roam. Their performances and their ability to attract audiences directly influence the circulation strategies of this circus group.

Finally, the circuses we call large or family structure circuses have a large physical capacity (more than 500 seats) and fixed teams with more than 30 members. They are usually owned by a family that refers to themselves as a circus family and resort to the work of several contractor families. These circuses have adopted an aesthetic derived from the circus of varieties, referred to as classic (Bolognesi, 2003; Silva, 2007). Such aesthetic is reinforced through the rhetoric of traditional circuses. Added to those, there are also large circuses that call themselves enterprises.

Enterprises have mixed the classical aesthetics with the theatrical one. They work with a plot, that is, a story that holds the different acts together. These circuses have greater resources of personnel and capital. Their large physical structures do not prevent them from moving and they resort to a variety of marketing resources to offer the show as an entertaining and fun product. Interestingly, despite resembling companies with no characteristics of the traditional circus family, these often stand on the foundation of circus families.

However, the similar aspects of daily circus management are the ones that concern us here. To fulfill this purpose, we analysed in the circus routine the semantic paths that are repeated or that have been significant for the subjects interviewed. These paths are supported by management practices and we found them in the following elements: the existence beyond the spectacle; the semantic course of the itineraries, which refers to the daily experience of moving from place to place and presenting itself as a physically mobile organization; and the show. The latter articulates with and appears as a presupposition of the other paths, since the daily activities and roaming have as their sole purpose the accomplishment of the circus performance. In a descriptive way, this paper shows within each semantic path how circuses narrate the everyday tactics and strategies that allow their survival against the standardization of management and the invention of new means of organization.

\section{The dynamics of circus activity and familiar relations}

The organizations analysed in this paper have proven to be rather complex. All of them, regardless of their structure, are supported by family relationships. A network of family bonds permeates all circuses, even those who perceive and call themselves businesses. It is a strategic web of relationships built so that circus families work by revolving around different circuses, designed to ensure the 
preservation of a common identity: the circus people. As expressed by respondent (R014), the artist would be part of a "chain":

"Generally speaking, the circus world is one big family, because today I'm working here, but perhaps in two months I'll be working at some other circus. But the link I have with this one remains, it's a chain, you form a circle. The circus is a rather closed world" (R014).

This historically constructed strategy preserves a web of family relationships, in which artists and family groups know one another and perceive themselves as participating in a common, "closed world". This network is regarded as necessary to ensure the appreciation of the circus activity. There is a relation of co-dependency among circuses: the small circus is the place where artists learn their acts (their very job) and develop their skills. In fact, managers of medium-sized circuses usually oversee new talents to be hired from smaller circuses. Likewise, the big circuses will find new performers in the medium ones. In other words, the big circus is the final stage that performers from small and medium circuses dream about, tactically speaking. Besides, visiting other circuses is seen as strategies to find reference for daily self-improvement, which creates the need for artists to relate with other performers. This network, circle, or chain enables individuals to maintain their circus identity as an artist and as a labourer.

In their routine, circus artists create tactics for their insertion and permanence in the show, that is, in the organization. The physical space of circuses makes room for the workplace and for domestic life. It sets its own practices, which demand that artists play several roles. The circus artist is in the circus as a jack-of-all-trades. They raise and disassemble the tents; they drive trucks and trailers; they look for spaces where they can set up; they carry out bureaucratic tasks; they install the lights, the sound and the water supply system; they perform as clowns, jugglers, trapeze artists, contortionists and equilibrists; they trade food and drinks in the tents; they advertise.

"I just hire people that can do everything. You'll be riding in the globe, but you'll also help me with the car. You will have to spread the word in town, help put the canvas up, sell popcorn and all (laughs)" (R001).

In some rare cases, especially in circuses that feature a more corporate structure, circus performers work only as artists. However, even these circuses cannot do without the articulation of networks among circuses, circus artists and families. Circus performers that roam with their family groups usually look for contracts to perform in more than one act and also in the daily operational functions. Subjects train themselves to perform both operational and artistic functions. Their mobility or ability to sell their family work for better prices depends on the working capacity of all members of the family group. This can relate to the multiple activities of an individual or the multiplicity of activities of the various members in a given family group. These aspects influence the negotiation between the artist and the circus owner.

"Sometimes the owner sets a payment. If you accept it, you'll go. If you decline, you won't go. You see? Sometimes it's like: 'the payment is X'; ‘- Oh, I cannot afford that'; 'Oh, so it won't be possible, maybe next time'. This is how it goes, usually the artist is the one who sets the price" (R047).

Respondent R016 explains that the negotiations involved several aspects, but mainly the artistic act the subject can execute. Artists who perform in more acts or acts seen as key in the traditional circus, usually comic (e.g., the clown) or risky (e.g., the trapeze) acts have greater tacit bargaining power:

"for in a circus, the clown is the host. People come to see the clown in the circus, I mean, the clown and the dangerous acts. Those are the acts that earn all the applause. The more things you show, the more money the circus can make. The more acts and shows you do, the more money you can earn here in the circus" (R016).

During wage negotiations, a representative of the family to be hired presents their labour offerings at different prices depending upon the demand conditions and willingness of the circus that intends to hire them. The strategy is to sell themselves and to have at least one family member hired by the circus. The others would gradually and tacitly join in later on, performing different acts. In other words, it is important to have the entire family hired, to ensure good income: 
"What we are offering here is my wife's show. She does the lyre. My son is a juggler and who can also ride the unicycle, or do a ribbon act. But as for now he's only juggling and there's my daughter, who is a contortionist" (R047).

The circus artists aim to work in circuses that pay the higher wages. To join or not to join a different circus is basically determined by the payment terms. The sale of food or any other product in the circus is valued by artists and represents a significant addition to the family income:

"The sale is what counts. Because sometimes the owner says 'I can pay you only so much, but I can give you the sales of cotton candy'. So, selling these things helps a lot” (R047).

Usually agreements are verbal and informal. On the part of the circus managers, weekly, cash payment practices prevail, along with a bonus for products sold in the circus. In some circuses, especially the larger ones, the distribution of sales is based on a non-explicit hierarchy among family clans, hired families and single individuals. Strategically, the sales of products that may generate larger profit, such as popcorn, potato chips and soda, are usually attributed to the owners of the circus and their immediate families. Other products such as sweet churro fritters and toffee apples tend to be distributed among the contractors' families, as well as the sales of toys, souvenirs and photographs. In some cases, owners retain all trades under their responsibility, sharing a percentage of such profits with the employees, as a means to improve remuneration.

Some individuals negotiate the right to sell products that generate more significant revenues because they offer artistic or operational work that is deemed necessary by circus managers. Thus, product sales is a tactical area for negotiations on the part of both circus managers and artistic and operational circus employees (De Certeau, 1990a, 1990b). In circus management, marketing products in the tent operate strategically to maintain the circus and the family groups living at its expense. Often the ticket profits are allocated to pay circus operating expenses, such as licenses, permits, electricity, water, fuel, wages, equipment replacement and structure maintenance. Families' personal expenses, such as food and clothing, are paid for exclusively with the money obtained from the sale of products in the circus.

Respondent (R001), who works in a medium-sized circus (200 seats), reported how they manage the circus resources. In this case, they seek to strictly separate the "box office money" from the "circus money" and the "sales money" from the "family money":

"The entire circus income comes from the box office. The sales done during the show belong to the families, so they can take care of their daily expenses. The circus' money goes to the circus maintenance: artists, employees, etc. We, the families, get by on that money from selling chips, popcorn .... If we [owners] start paying salaries, then we won't be able to keep the circus" (R001).

R056 works in a smaller circus with a smaller audience and also claims to spare part of the box office revenues to keep the circus. However, since sales profits are not sufficient to maintain the family group, a certain percentage of the money collected from the ticket sales is used to compensate the family of artists. R056 reinforces the importance of sales when detailing the variety of products they offer, but the subject also attempts to relativize such sales by calling them "modest". There is confusion between the "I" - the circus owner - and the "mine" - the circus itself. In other words, between the subject and the organization. Therefore, the expression "I have to get by on" suggests the difficulty of separating the circus expenses from the personal, family ones.

"In this circus, about $60 \%$ of the box office is to be shared among all. I get by on the $40 \%$ remaining, my part and some to keep the circus working. Each family has a modest share of sales, beyond the percentage, as a bonus... My pay is just the circus', the circus' revenues. I have no share of the sales or anything. It's all theirs. My share is only the $40 \%$ I get by on" (R056).

The sale of products, as outlined above, corresponds to a large part of the families' incomes at small, medium and large circuses. The show and the strategy of selling products make up the payment of artist and their relatives. From this perspective, staying for too long at a single place ends up depleting the effectiveness of such strategy: 
"But we don't stay for too long, we move all the time. We make money by roaming. There's no point in staying. If we stay, we won't sell anything, only the owner will make any cash. So we move, in each city you arrive there's new money, it's a different audience, so that's the advantage" (R082).

The respondent emphasizes the importance of roaming, which contrasts positively to staying. According to the speech, staying too long at a place results in no money. Therefore, roaming involves the possibility of making "new money" and the fact that "we make money by roaming". Roaming brings new audiences and new consumers to the shows and is a strategy for the survival of the circus business.

\section{Roaming: an ancient trick to go up in the world}

Where to go? How long to stay? These are frequent questions in the everyday life of a circus troupe and they are usually answered with the phrase "it depends", as referring to what is undefined. Depending on several factors does not imply the absence of planning in circus management; by contrast, it actually shows the ability to create new strategies in the face of unforeseen events. Circus workers claim to have knowledge of the various possibilities of unforeseen events that may influence their ability and need to roam. The main one is the absence of audiences and the consequent lack of financial resources.

"It depends on what is going to happen. Moving from one city to another has costs such as fuel, labour, water, light, lot rentals, tires, maintenance in the days before the premier, which always takes place on Fridays" (R001).

"The circus is all about that, you move from town to town, but business is bad, then you decide to move away thinking 'I'm going somewhere, go up in the world, I'm going to make me some cash"' (R043).

"And it all depends on the local folks ... We stay for as long as our needs are met.... Because the circus, you know, although it is entertainment, a millenarian game, it also depends on profits" (R014).

Respondent R043 describes an imaginary idea that always circulates between circus workers: the idea that if in a city the show is going wrong financially, in another one it may be better accepted and all can make money, hence "going up in the world". However, for as much as one may know about the cities they go to, every place welcomes the circus differently. There is always a cost involved, as (R001) points out, and this may be expensive. However, respondent (R014) articulates that it all depends on whether the show is meeting their financial needs. There is explicit denial of the concept of a millenarian art that does not depend on or have to resort to the goal of making profit.

An unforeseen event can always arise is another circus on the same route that had been originally planned. A circus may get to a town before another one and collect all the money the latter aimed to achieve. At this point, what really counts are the tactics, that is, to rethink about situations and improvise as artists do in their shows, by creating new routes and even including new ones in the usual roaming itinerary.

"Let's suppose we ... get there and a circus arrived before us. If there's already a circus there, we can't go, because they'll be earning all the locals' money. So, we must come up with a new route, even if it's one we don't know at all" (R081).

Another unforeseen element is not reaching the audience due to local activities with which the circus cannot compete. Respondent R094, who works for a small circus around small towns and R092, who works for a large circus on the outskirts of large cities, have both mentioned such unpredictability:

"We got to the town and the farmer was having a party. He'd killed four cows and four pigs. The party went on for a week...; It didn't rain for the whole week, but when the show time came... it rained! People's birthdays are on Wednesday, but they decide to celebrate on Saturday... Or they get sick on Tuesday, but will only die on Saturday afternoon (laughs), at the very time of the shows" (R094). 
"We go down to Santa Cruz (RJ), but there's already a circus there, we can't stay there, then we move to São João do Buriti, but there's going to be a party or a rodeo there, then we can't compete with Luan Santana [famous country singer], then we end up in Barra da Tijuca” (R092).

There is also a big problem (always somewhat expected) the (un)responsiveness of the local public authority, responsible for permitting the legal establishment of the circus in the locality.

"The fire department, the engineers, they have so much bureaucracy against the circus that it gets too difficult to complete a full route. Because we get to a town and sometimes the mayor thinks he's the king of the town: 'I don't want no circus in my city"' (R022).

In addition to the problems reported above, large circuses also report difficulties in completing a given route due to the lack of physical space with public accessibility (public transportation) and/or compensatory benefit to the circus with regard to the rental price.

"Nowadays, the most difficult challenge of large circuses is not having a space where to put the tent up. Most of the times I have to go away from big cities and this ends up troubling access to audiences, ... If we are next to a mall, we'll have an audience; if we are next to a subway station, it'll be easier for people, more accessible. So, when we analyse a spot to set the tent up, I'll always pay attention to all these factors" (R102).

In face of the unexpected event of getting into a collision course with another circus, or of not having audience due to local festivities, or any other unforeseen situation that makes it impracticable for the circus to stay or reach a given community, the tactics that will be used later as alternative strategies are created by the circus subjects. The circus artists change the script, as reported by R081. They find alternative towns on a given route, making the unforeseen events more controllable. This is what is defined as "a bit unpredictable" in the everyday of roaming circuses.

"We can't decide on a path, an itinerary, because there are setbacks.... Circuses are a bit unpredictable" (R014).

Prior knowledge of the various unexpected events shows that the circus constantly deals with different realities, which are not subject to control and demand great flexibility in everyday practices. Those involved with the circus seem to develop a sort of flexibility, both body-wise (as seen in the artistic acts) and contract-wise (managers want artists who also work as manpower, assembling and disassembling the circus, for example), or even as to the redesign of tour routes or negotiating with local authorities.

Flexibility is linked to the circus art and practice - to live, to work, to manage, etc. Such practices arise from the experiences in everyday circus life; i.e., flexibility, which is established from the moment that the subjects can invent and create with what they are given as a result of the experience of living in a circus. The circus labour appropriates the new spaces, acting proactively, reversing objects and legal codes, seeking to use them to their advantage, they do not act passively and uniformly with conformity to the impositions of the market and social powers. The concern to maintain an aesthetics matrix of circus spectacle shows that they do not conform to the market, denying the commodification of their work is expressed in strength and by maintaining an aesthetic matrix of a circus characterized as traditional.

\section{Our show is in the ring, the ground covered in sawdust, to give off that circus atmosphere}

Circuses managers conduct the dynamics of roaming in conjunction with the possibilities they have to design their show. The residence time in a locality is defined exclusively by the audience success or failure and both are related to the possibilities of a circus to attract audiences.

"Here in this city, it is no good to stay past Sundays if audiences are going down, it doesn't pay to stay the second week, due to the expenses the circus has" (R046). 
"Today, if a circus stays longer than four days in a town, it won't do anything else. We only stay for four days in this town, because the show is always the same. Once you've seen it, you won't come back. Then after four of five days, we have to roam. If we stay longer, nobody comes to the circus show" (R048).

Circuses with the largest number of family groups - and therefore with more artists and a wider range of acts - can extend their stay for a longer period. On the other hand, small circuses featuring varied performances, especially those that add theatrical parts to their repertoire, have also been able to extend their stay for several weeks at a given district or locality.

"There are circuses, for example, that stay up for a month at a town, because they work with comedy and drama. The first part of the show is varied and the second has drama and comedy. Therefore, their show gets longer and more varied. So there's a whole supporting scheme to stay for one or two more weeks, if that's the case. But it all depends a lot on the turnover" (R046).

"In the cities we have been to, we have tried to get the locals used to going to circuses more often. All small towns, where the people like to go and already know my circus .... But I have my daily 'habitués', so we keep the customers happy" (R023).

Therefore, reaching the audience directly relates to the assets and attractions a given circus has to present. A few of the analysed circuses present different shows and this enables them to win over the audience. Returning to the same location often becomes a business strategy of such circuses. The show sustained on a large repertoire of circus-theatre pieces convinces the audience, getting them used to attending the circus shows when the troupes arrive in their town. Thus, the repertoire of a circus occupies an important strategic position in this kind of organization. Some of the large circuses that feature a fixed repertoire with minimal variation between shows can settle for long periods in a single location. In this case, the strategy seems to be depleting the audience and resorting to intensive advertising everywhere near the circus, and this situation is frequent in large cities. Medium and large circuses seek to set up in smaller towns, not capitals, in order to obtain maximum capacity for only a few days.

Many of the visited circuses seem to share a common vision of what they want in a circus show. This idea is inscribed in the very concept of traditional and family circuses. There is an idea of us that refers to circus families to the detriment of the idea of them (those who do not belong to the clan). This familiar structure enables the establishment of common visions about how to execute the circus show. Traditional circus is based on laughter and risk (Bolognesi, 2003). For the traditional circus artist, the show has to make the audience laugh and to feature tricks, that is, performances that subjects who are not circus performers are not able to achieve.

"You know, circuses are a risky thing. If they weren't, they wouldn't exist at all. For instance, you leave your house to come to see us, and then you want to see something different. The locals come to see us so they can see different things that they usually don't have in town. A woman spinning her neck, doing acrobatic stunts, a knife thrower, the globe of death. People want to see the danger, you know? Afterwards, they want to laugh at the clown. Otherwise, people would find no fun in going to a circus" (R016).

“Here's what I think: nowadays, many circuses do well because they're a family. The circus can be small, but it has to have good acts, such as the trapeze, the globe of death, the clowns, those things that cannot be missing in a circus show" (R112).

Setting the number of acts complies with a fixed time limit and the range of attractions available. If that particular circus has a group of artists with diverse abilities, it usually designs the show blending greater impact numbers with a few comic numbers. The presence of comedies, especially in small circuses, also indicates different dynamics for the performances.

"I like spectacle circus when I enact a comedy. There are eight acts at the most, plus the clown show. So, when it's a regular performance, I do the following: I'll have eight acts in the first part and three on the second, you see? That adds up to eleven acts. The total show will last for around two hours, including the break. If it's longer than this, it gets boring" (R023). 
"Well, our show has the trapeze, the globe of death, and the silver man, which is a great act. We also have acrobats, magicians, and clowns. It's a quite diverse show, it reaches all tastes without being too long. It's an hour and a half long” (R093).

According to the accounts collected, small and medium circuses are often not concerned about having a plot, such as a stage play or a theme that connects the various acts. The show is flexible, but usually consists of a variety of independent acts, as seen in the speeches above. However, in some larger circuses, there is demand for something that holds things together, like a plot.

"So, we change the theme of our show every two or two and a half years. We pick the theme so that it can last for two years and a half, which is the total time of the tour. In our current show, we tell a little bit of the history of circuses around the world. The previous one was the variety format and we're already thinking about the next one" (R102).

In circus shows, a recurrent tactic (De Certeau, 1990a) is the use of attractions that have achieved success in mass media. The use of such attractions in large and structured circuses occurs formally, under agreements that establish how the circus can use a given product from popular media (Quaresma, Silva, \& Carrieri, 2014). In smaller circuses, however, the use of these attractions is done informally, with covers, without any license or right of authorship, as R067 ironically suggests.

“One week I'll do the Galinha Pintadinha [Brazilian children cartoon TV character], I have the Galinha Pintadinha, the copyrights are mine, I made them... [laughing loud]” (R067).

"An outside attraction happening in the circus, ... every circus that features an attraction [like that] brings audience to the show. The people go see that attraction and ends up loving the circus. Then you ask why don't they just come to see the circus? We even used to have the Patati \& Patatá show [Brazilian circus clown duo, licensed as a copyrighted product] and it would sell out. Right after, though, we had our own show out, without any outside attraction, and nobody showed up! It was awful! So, if you announce Patati \& Patatá, it sells out” (R112).

According to R112, even when perceived from an exterior perspective, copyrighted media attractions are valued for their ability to attract audiences. The circus artist's frustration is explicit when the subject reports to have sought to accomplish a show without a famous media attraction and nobody attended. The horror in the face of an empty audience at a traditional circus spectacle is confronted with the chance for big audiences by incorporating a media attraction.

The contrast between the attractions known by artists, belonging to their history, and the new proposals on how to conduct the show, are evidenced in the speeches that refer to the Canadian company Cirque du Soleil. Cirque du Soleil is referred to as an element of distinction between artistic projects of a circus that calls itself traditional and other circus, regarded as modern or contemporary.

"Our show is old-fashioned, so to speak. People came with that rabble about changing the circus, but I said: 'Speaking is easy, but I want to see who's going to give away the gear necessary for us to change and become Cirque du Soleil' (laughs). I said: 'I'd rather carry on with my Indian rope trick, which I taught my grandchildren, with the lyre act, which I learned from my grandfather. My space bike'. Anyway, we still do our old acts" (R056).

"We try to catch up, but without losing sight of tradition. We have the modern structure, with sound and lighting, but there's also a ring. Even without any animals our show is in the ring, the ground covered in sawdust, to give off that circus atmosphere. There's a clown, a ringmaster... These days people don't use ringmasters anymore. We try to blend both things" (R001).

The authenticity of traditional circus is attributed to various objects such as the sawdust that covers the tent ground, the clowns, the lyre act, the Indian rope trick, the ringmaster, the space bike act, among others, as well as the family relationships and the contact with the audience. The variety of elements, the learning and the artistic performance are attributed to the concept of traditional circus show. 
On the other hand, technology is attributed as a distinctive mark of Cirque du Soleil. The prosody about Soleil is always mentioned with negative associations and its name is used to qualify absence, inefficiency and something lacking. The speeches of the respondents refer to the concept that the traditional circus is always based on funny and risky acts, which aim to create in the audience emotional reactions such as those mentioned by R112. According to the speeches, these are not found in the Cirque du Soleil shows, since they are characterized as cold and pasteurized by technology:

"Nowadays, Cirque du Soleil has a show with no artists; it's just sound and lighting. The audience has the impression to be watching something, but it is not a real act, it's just technology" (R082).

"You go to Circus de Soleil and the show is cold, the audience is cold... It's all cold. In a real circus you'll be scared to death and laugh your butt off, because that's what traditional circus is all about, funny and risky acts, and it's very good (laughs)" (R112).

According to the respondents, the traditional circus show is the one designed to produce sensations of joy and excitement. The one resulting from the work of family groups, the collective and multifaceted work of the individuals who are integrated into the circus. Added to that, the work of individual artists and their acts is what has allowed the persistence of such everyday circus strategies and tactics, as presented next.

\section{Analysis of Circus Tactics and Strategies}

Circuses are practised organizations like any other and, as such, they are part of the local socialhistorical reality, reconstructing themselves every day. In our view, organizations are not given realities, lost in space and time, but they are always performing in their ever-changing routine. A circus is not only a physical space with a canvas and a ring. It is also a space for the configurations of subjects such as artists, workers, managers, owners and even the audience (loyal followers or otherwise). The speeches collected in the visited circuses make one think about those subjects' experiences. Such experiences are established from the moment when subjects come to believe in this form of art, in the format of the show, in the nomadic way of life, and create opportunities for the audience to "be scared to death and laugh their butts off" (R112). This practical experience creates flexibility that makes this type of art perpetuate through generations.

Various strategies (De Certeau, 1990a, 1990b) to confront the circus routine have been reported. We can state that some of them are common to various of the visited circuses. These allow such organizations to reproduce in time and space, keeping their own characteristics, which are constantly repeated, transformed, re-signified and updated. One of the first strategies observed is the establishment of a network, an intra/inter-organization of subjects. This strategy occurs within relationships that are barely collaborative among organizations (as the competition for squares and places to raise the tent has proven), but which allow the movement of circus subjects among them. This creates a world of workers and nomadic artists who roam around as much as the circuses themselves.

The second strategy is the articulation of the family core and the workplace unit. Roaming favours the creation of circus family cores. For some of the familiar circuses, working in the circus is seen as the only possible way to make a living, since the social and legal aspects of payment are absent. The capitalist calculation of profit would cease to exist, being replaced by the discourse of meeting the needs and searching for the reproducibility of the family core. This does not mean that circuses' owners and managers of circuses are not capitalists, because there is possibility of hiring labour, establishing an exploitation relationship that is often in the margins of a formalized society. However, the concept of family reproducibility permeates the position of circus owners and contracted families.

The third strategy is directly linked to the maintenance and reproducibility of the circus activity. Traditional and/or business circuses have commerce as a major source of economic resources, which ensures the survival of the activity and of labourers. However, in traditional circuses (non-business), the 
entire food and souvenir trade done under the canvas constitutes financial resources to be used to maintain the family group in question. Therefore, there is a tacit division: the money collected at the box office is aimed at maintaining the circus structure and circulation, while the money from the sale of foods and products (which can be as varied as possible) is designed to support the family responsible for their sales.

A fourth strategy refers to the constant change of place, that is, roaming. Mobility is seen as a necessary strategy in the quest for audience and income. The mobility and the circus families are interdependent realities. How could they roam indefinitely without the presence of their families? How can a family make a living without roaming and seeking new audiences? The circus goes where the audience and the money are. While there is an audience, a given circus can extend its season. Associated with this strategy, there is a tactic of creating new routes, to subvert the planned routes so that the unexpected may happen.

This form of dealing with the unpredictable has allowed us to observe various creationsinventions, which value the arts of doing (De Certeau, 1990a) from a circus standpoint. In circus management, subjects live quite close to the new, to the unknown, to the unforeseen. Constant mobility causes uncertainty. Uncertainty about the audience, the public authority, the obtainment of land to raise the tent, the route to follow, the duration time, etc. The town dependency causes the greatest uncertainty possibility of survival of the organization. The informal working relationships also cause uncertainty as to the artist's willingness to take part in the show; their mobility and lack of labour bonds allow constant workplace change, aimed at eventually reaching the top, that is, larger circuses. On the other hand, the loss of performers on the part of circuses brings change and inconstancy into the shows. The everyday of a circus is marked by uncertainty. Dealing with it is part of the life and management of a circus.

As far as labour is concerned, individuals create their own tactics (De Certeau, 1990a, 1990b) to exist and reproduce in the circus world. Versatility and artistic uniqueness are these very tactics. The versatile artist has been configured as a necessity in small and medium-sized traditional circuses. Performing several acts and meeting different operational demands are daily activities that take place in these circuses. Artistic uniqueness, as a result of hard work, and the aspects of the invention of the subjects in the creation of their acts, are always desired. However, uniqueness may end up breaking family ties, since it allows artists to pursue careers in larger circuses.

De Certeau (1990a, 1990b) proposes that the study of the everyday enables the recognition of the singular cultural expressions and the analysis of how those who produce these expressions appropriates the meanings, highlighting resistance, showing ways to circumvent the market rules and norms; inversions that subjects operate on objects in the codes for its use in their way, in response to their interests. The persistence of circus organizations nowadays is a picture of these everyday subversions. Unlike other kinds of performing arts, like theater or dance, the circus is entirely dependent on the audience. Audience has size, has quality, a theater circus audience is different from a small circus audience circulating on the outskirts of the great city, which is different from the circus audience with great attractions in major cities. The Circus adapts to your audience, but there is a complete commodification of artistic circus work. There are tactics to enhance a performance with more shows that use characters from popular media goes against what many people believe is correct. There is resistance, because for the traditional circus media characters are something extra offered to the audience, and many wish to keep traditional acts to maintain the true circus essence (Aguiar \& Carrieri, 2016).

In reality, the circus resists the possibility of succumbing, as character acts borrowed from media aren't actually regarded by circus workers a corruption of their art. This is a superficial analysis when it comes to thinking about artistic processes in relation to media acts, as for the circus worker this is just one more tactic to keep laughing and facing risk (Bolognesi, 2003). Here there is an appropriation of a practice with a meaning to the circus worker of externality. For circus workers the character acts do not belong them, but are practices others use to sustain a show that belong to them, a particular form of organization. In De Certeau (1990a) the everyday activity is creative, it is in the everyday life where practices are repeated. But the circus does not have a everyday repetition, changing, roaming and coming 
across new audiences imply a constant readiness for the reflectivity to change the way of doing and relating, which allows it to persist as an organization over time.

\section{Final Thoughts}

This article has investigated the everyday of Brazilian circuses as well as their practices, strategies and tactics. As for the strategies pointed out, there is one among them that pervades all the circuses studied and is linked to the concept of a traditional-act show. These acts construct the identity of the circuses analysed. They refer to a timeless past; they are the past and the present of circuses. Therefore, the strategy of the circus to persist is rooted in the traditional acts, in their ability to make the audience be scared to death when watching the dangerous performances and laugh their butts off at the comic acts. However, the tactics of using copyrighted character attractions to attract a larger audience can be seen as a necessity, for they are economically attractive.

The traditional circus acts are sometimes reduced to the presentation of outside attractions, such as TV shows Patati \& Patatá, Galinha Pintadinha, and Turma da Mônica (licensed products). We have noted, in this regard, the subversion of their very tactic, when small and medium circuses, with little economic power, create cover shows and add renowned character products from the media to their repertoire without paying any royalties and copyrights. Such attractions are temporary, they are not the ones regarded as the most important. They are only resorted to at specific times and contexts. Their only purpose is to attract audiences and make money.

We can think about the routine, strategies and tactics involved in circus management as everyday, reinvented ways of creating subjectivities. These are translated in the interactions established between the circus and the cities it visits, as well as the interactions of circus artists with audiences and members of the local authority; likewise, the interactions with friends from other countries, cities, and circuses. The circus routine enables the construction of strategies and tactics that show, above all, the ability of those involved to respond to the present moment and carry on with the wonderful, magnanimous, amazing, grand and spectacular world of circuses.

Finally, the study with and in the organization everyday life (Ferraço, 2007) is another resource in understanding the social relations that are established in what we call enterprises, businesses, organizations. Everyday life can be studied as a category of analysis, in order to analyse the everyday situations related to people's daily lives, their knowledge, their experience with management, labor, and the world. For Chauí (2001, p. 8, our translation) "everyday life is all made of silent belief, tacit acceptance of evidence that never question because they seem natural, obvious". In this sense, by bringing the everyday to organizational studies, it is possible to question the way we contemplate management, the naturalization of models, and forms of teaching management, without questioning the production of institutionalized scientific knowledge.

Research about the everyday needs to be interdisciplinary and relate different knowledge to the phenomena that occur in the everyday lives of individuals, focusing on the survival of the social group involved, and of the families and businesses. There are several possibilities that interdisciplinarity can bring, in this paper was pointed out authors like Heller, Lefebvre and De Certeau who researched the everyday differently. We chose De Certeau to direct our analysis and search for the everyday for circus workers, their social relationships and their business - the circus, an activity and a business which requires creativity, inventiveness and at the same time a routinization of processes such as roaming, assembling the facilities, opening the show every week, among others.

In this research we observed that we must always establish relations of everyday practices to the social conditions in a time and space because the everyday changes, the social relations change, bringing out different ways of organizing the work, the business, the social relations, which also are neither uniform nor definitive. But we must bear in mind that there are of course risks as in any research. One 
of the main risks is to subvert the everyday as a category of main analysis and only characterize it as having a secondary role in the conduct of research and analysis, that is, only serving as a mere exemplification or exemplification of organizational day by day to think about management. This must be a constant concern of researchers who proposes to study the management and the everyday lives of people in organizations and work.

\section{References}

Aguiar, A. R. C., \& Carrieri, A. D. P. (2016). "Água de lona" e "sangue de serragem" nos discursos de sujeitos circenses. Organizações \& Sociedade, 23(77), 247-262. http://dx.doi.org/10.1590/19849230774

Bolognesi, M. F. (2003) Palhaços. São Paulo: Unesp.

Callinicos, A. (1989). Making history. Cambridge: Polity.

Carrieri, A. D. P. (2012). A gestão ordinária. Belo Horizonte, MG: Universidade Federal de Minas Gerais.

Carrieri, A. P., Perdigão, D. A., \& Aguiar, A. R. C. (2014). A gestão ordinária dos pequenos negócios: outro olhar sobre a gestão em estudos organizacionais. Revista de Administração, 49(4), 698-713. http://dx.doi.org/10.5700/rausp1178

Chauí, M. (2001). Convite à filosofia. São Paulo: Ática.

Cooper, R. (1986). Organization/Disorganization. Social Science Information, 25(2), 299-335. http://dx.doi.org/10.1177/053901886025002001

De Certeau, M. (1990a). L'invention du quotidien, I: arts de faire. Paris: Gallimard.

De Certeau, M. (1990b). L'invention du quotidien, II: habiter, cuisiner. Paris: Gallimard.

Del Priore, M. (1997). História do cotidiano e da vida privada. In C. F. Cardoso \& R. Vainfas (Orgs.), Domínios da história: ensaios de teoria e metodologia (pp. 259-274). Rio de Janeiro: Elsevier.

Duarte, R. H. (1995). Noites circenses: espetáculos de circo e teatro em Minas Gerais no século XIX. Campinas: UNICAMP.

Ferraço, C. E. (2007). Pesquisa com o cotidiano. Educação e Sociedade, 28(98), 73-95. http://dx.doi.org/10.1590/S0101-73302007000100005

Fleming, P., \& Sturdy, A. (2009). Bringing everyday life back into the workplace: just be yourself! In P. Hancock \& M. Tyler (Eds.), The management of everyday life (pp. 199-216). Hampshire: Palgrave MacMillian.

Freitas, V. V. (2008). "Unicamente por veneração e respeito": os irmãos brancos e a invenção do cotidiano em uma irmandade leiga do Recife - século XVIII. Mneme, 9(24), 1-7.

Gardiner, M. (2000). Critiques of everyday life: an introduction. London: Routledge.

Garfinkel, H. (1967). Studies in ethnomethodology. Englewood Cliffs, NJ: Prentice Hall.

Goldenberg, M. (2002). A arte de pesquisar: como fazer pesquisa qualitativa em Ciências Sociais (6a ed.). Rio de Janeiro: Editora Record. 
Goodman, L. A. (1961). Snowball sampling. Annals of Mathematical Statistics, 32(1), 148-170. Retrieved from https://projecteuclid.org/download/pdf_1/euclid.aoms/1177705148

Goonewardena, K., Kipfer, S., Milgrom, R., \& Schmid, C. (Eds.). (2008). Space, difference, everyday life: reading Henri Lefebvre. New York: Routledge.

Hancock, P., \& Tyler, M. (Eds). (2009). The management of everyday life. Hampshire: Palgrave MacMillian.

Harvey, D. (2002). The condition of postmodernity. Cambrigde, MA; Oxford, UK: Wiley-Blackwell.

Heller, A. (1984). Everyday life. London: Routledge \& Kegan Paul.

Herners, T. (2008). Understanding organization as process. New York: Routledge.

Herners, T., \& Maitlis, E. (2010). Process, sensemaking, and organizing. Oxford: Oxford Scholarship Online.

Lefebvre, H. (1974). La production de l'espace. L'Homme et la Société, 31(1), 15-32. Retrieved from http://www.persee.fr/doc/homso_0018-4306_1974_num_31_1_1855

Levigard, Y. E., \& Barbosa, R. M. (2010). Incertezas e cotidiano: uma breve reflexão. Arquivos Brasileiros de Psicologia, 62(1), 84-89. Retrieved from http://seer.psicologia.ufrj.br/index.php/abp/article/view/575/396

Maravelias, C. (2011). The managementization of everyday life. Ephemera, 11(2), 105-121. Retrieved from http://www.ephemerajournal.org/sites/default/files/11-2maravelias.pdf

Marre, J. L. (1991). História de vida e método biográfico. Cadernos de Sociologia, 3(3), 89-141.

Parker, M. (2002). Queering management and organization. Gender, Work and Organization, 9(2), 146166. http://dx.doi.org/10.1111/1468-0432.00153

Parker, M. (2011). Organizing the circus: the engineering of miracles. Organization Studies, 32(4), 555569. http://dx.doi.org/10.1177/0170840611403668

Quaresma, E. A., Jr., Silva, E. R., \& Carrieri, A. P. (2014). As alianças estratégicas no picadeiro da arte/negócio circense. Revista de Administração Mackenzie, 15(3), 101-131. http://dx.doi.org/10.1590/1678-69712014/administracao.v15n3p101-131

Rowlinson, M., \& Carter, C. (2002). Foucault and history in organization studies. Organization, 9(4), 527-547. http://dx.doi.org/10.1177/135050840294002

Silva, E. (2006). O ensino de arte circense no Brasil: breve histórico e algumas reflexões. Retrieved from http://www.funarte.gov.br/portal/2009/12/08/escola-nacional-de-circo-um-historico/

Silva, E. (2007). As múltiplas linguagens na teatralidade circense: Benjamin de Oliveira e a teatralidade circense no Brasil. São Paulo: Altana.

Sousa, A., Filho, (2002). Michel De Certeau: fundamentos de uma sociologia do cotidiano. Sociabilidades (USP), 2(2), 129-134. 


\section{Authors' Profiles}

Ana Rosa Camillo Aguiar

Av. Antônio Carlos, 6627, 31270-901, Belo Horizonte, MG, Brazil. E-mail address: rosacamillo@gmail.com

Alexandre de Pádua Carrieri

Av. Antônio Carlos, 6627, 31270-901, Belo Horizonte, MG, Brazil. E-mail address: aguiar.paduacarrieri@ terra.com.br

Eloisio Moulin de Souza

Av. Fernando Ferrari, 514, Goiabeiras, 29075-910, Vitória, ES, Brazil. E-mail address: elomoulin@gmail.com 